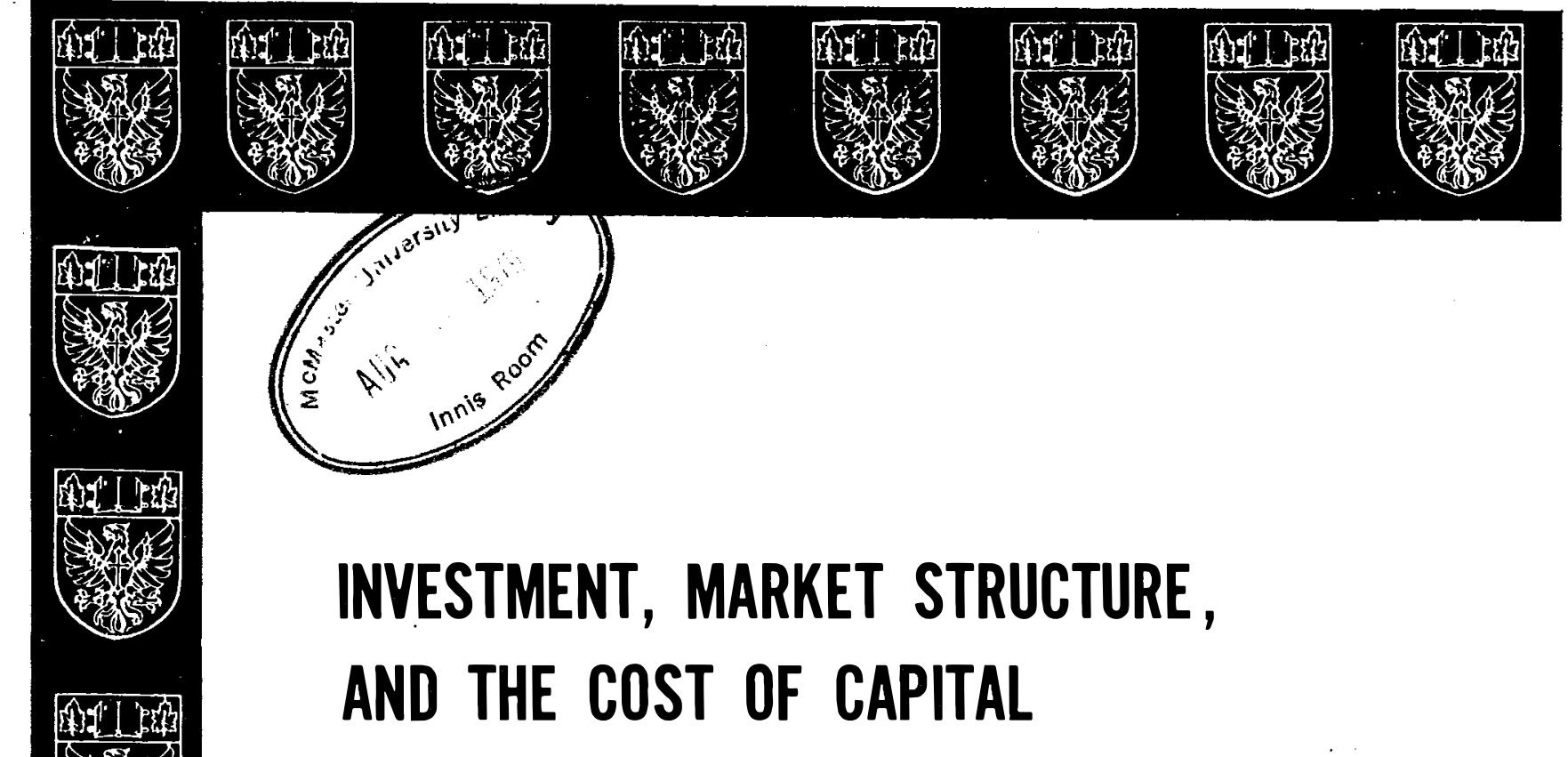

By

V. AIVAZIAN and J.L. CALLEN

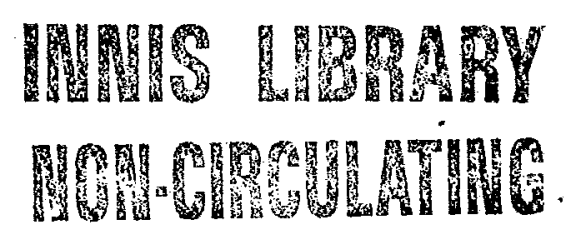

FACULTY OF BUSINESS

MCMASTER UNIVERSITY

HAMILTON, ONTARIO

Research and Working Paper Series: No. $134 a$ July, 1977 


\section{Investment, Market Structure, and the Cost of Capital}

by

Varouf Aivazian and Jeffrey L. Callen

McMaster University

$$
\text { July, } 1977
$$

Revised

September, 1977 
The seminal articles by Modigliani and Miller (1958, 1963) have led to the misconception that the optimal investment strategy of an all equity firm is to set the marginal return on investment equal to the rate of return required by shareholders. Two recent papers have dispe1led this notion by arguing that the firm's optimal investment response is highly sensitive to the nature of the investment process so that the cost of equity capital is not always synonomous with the required rate. E1ton and Gruber (1976) demonstrate that the marginal return on investment should be less than or greater than the rate of return required by shareholders depending on the evolution of the investment path over time. Gordon and Gould (1977) show that, within the context of the constant dividend growth model, the marginal return on investment should be less than the required rate.

In this paper, we will specify the conditions which determine the relationship between the marginal return on investment and the rate of return required by shareholders. It is shown that the nature of the relationship is sensitive not only to the dynamics of the investment process but also to the industry market structure. In what follows, we first provide the intuitive background to motivate our results and then the formal analysis.

Investment Externalities and Market Structure

It is not difficult to conceive of the fact that the current investment activities of each firm within an industry determines the future investment opportunities of the industry as a whole. The effect need not be unidirectional. Current investment activities may either increase or decrease future industry investment opportunities. Either 
of these circumstances implies that externalities may ensue from the firm's current investment activity. The existence of these investment externalities, as well as their extent, depends crucially on how exclusive are property rights over future investment opportunities. The degree of exclusive property rights that a firm has over future industry investment opportunities is, in turn, a function of the firm's market power and, hence, industry structure. Where there are exclusive property rights to these opportunities, as in the case of a monopoly or collusive oligopoly, the externalities will be completely internalized by the firm in arriving at its optimal investment strategy. The externalities are simply co-opted and disappear. On the other hand, as long as property rights are non-exclusive, as Coase (1960) argues in his pathbreaking article, the externalities remain. Therefore, in the polar case of a competitive industry, future investment opportunities will be treated by each firm in the industry as a common property resource, a free good. ${ }^{1}$ Each firm will disregard the impact on future industry investment opportunities engendered by its own current investment activity. If we extend the common property resource analogy to a non-collusive oligopoly, we should expect that, as the number of firms in the industry is reduced, each firm internalizes a greater proportion of its impact on future investment opportunities. ${ }^{2}$ Therefore, the rate at which the industry investment opportunities are exploited by each firm is a function of the industry structure as well as the dynamics of the industry investment process. 
The Mode1

We begin the formal analysis by considering the investment strategy of a Cournot oligopolist trying to maximize the (expected) net present value of future cash flows discounted at the rate of return required by shareholders. ${ }^{3}$ In his typically myopic fashion, the Cournot oligopolist assumes that his investment strategy has no effect on his rivals and he takes their investment behaviour as given. In fact, the average return on investment which the oligopolist earns is a function of all market participants both at a given moment in time and over time. Specifically, this model of oligopoly behaviour can be represented by:

Maximize

(1) $\mathrm{V}^{\mathrm{j}}(0)=\int_{0}^{\infty} \mathrm{e}^{-k t}\left[\mathrm{E}^{\mathrm{j}}(t)-\mathrm{I}^{\mathrm{j}}(\mathrm{t})\right] \mathrm{dt}$ subject to:

(2) $\frac{d E^{j}(t)}{d t}=r(I(t), t) I^{j}(t)$
(3) $\frac{d r(t)}{d t}=F(I(t), r(I(t), t), t)$

where $j \quad=$ the $j^{\text {th }}$ firm in the industry, $j=1, \ldots, m$ $\mathrm{V}^{j}(t) \quad=$ value of firm $j$ at time $t$

$\mathrm{k} \quad=$ rate of return required by shareholders

$E^{j}(t) \quad=$ earnings of firm $j$ at time $t$

$\mathrm{I}^{\mathrm{j}}(\mathrm{t}) \quad=$ investment of firm $\mathrm{j}$ at time $\mathrm{t}$

$I(t) \quad=$ total industry investment at time $t, I(t) \equiv \sum^{m} I^{j}(t)$

$j=1$

$r(I(t), t)=$ industry average return on investment at time $t$ 
Constraint (3) requires some brief comment. This constraint represents the dynamic evolution of the industry's investment opportunities over time. It is assumed that the evolution of the industry average rate of return is a function of the current average rate, current investment and, perhaps, time itself. The function $F$ is assumed to be well behaved. $^{4}$ Other than that, $\mathrm{F}$ can take any form whatsoever although three polar cases are representational:

(i) future industry investment opportunities are an increasing function of current investment decisions, i.e. $\frac{\mathrm{dF}}{\mathrm{dI}}>0$

(ii) future industry investment opportunities are independent of current investment decisions, i.e. $\frac{\mathrm{dF}}{\mathrm{dI}}=0$

(iii) future industry investment opportunities are a decreasing function of current investment decisions, i.e. $\frac{\mathrm{dF}}{\mathrm{dI}}<0$

Clearly over any time horizon many combinations of these three cases are possible. In a life cycle theory of industry development, for example, initial investment would result in new investment opportunities, eventually leading to a steady-state and, finally, industrial decline. This scenario is illustrated in Figure 1 below. On the other hand, in the case of IBM, $\frac{\mathrm{dF}}{\mathrm{dI}}>0$ appears to be the rule for any conceivable finite time horizon as in Figure 2 below.

Market Structure and the Cost of Capital

The optimal solution to the oligopolist's investment problem is solved by standard control theory techniques in the Appendix. It is shown that the oligopolist's optimal response is governed by the equation: ${ }^{5}$

(4) $M^{j}(t) \equiv r+r^{\prime} I^{j}=k-e^{k t} \frac{d F}{d I} \int_{t}^{\infty} I^{j} e^{-k \tau} d \tau$ 


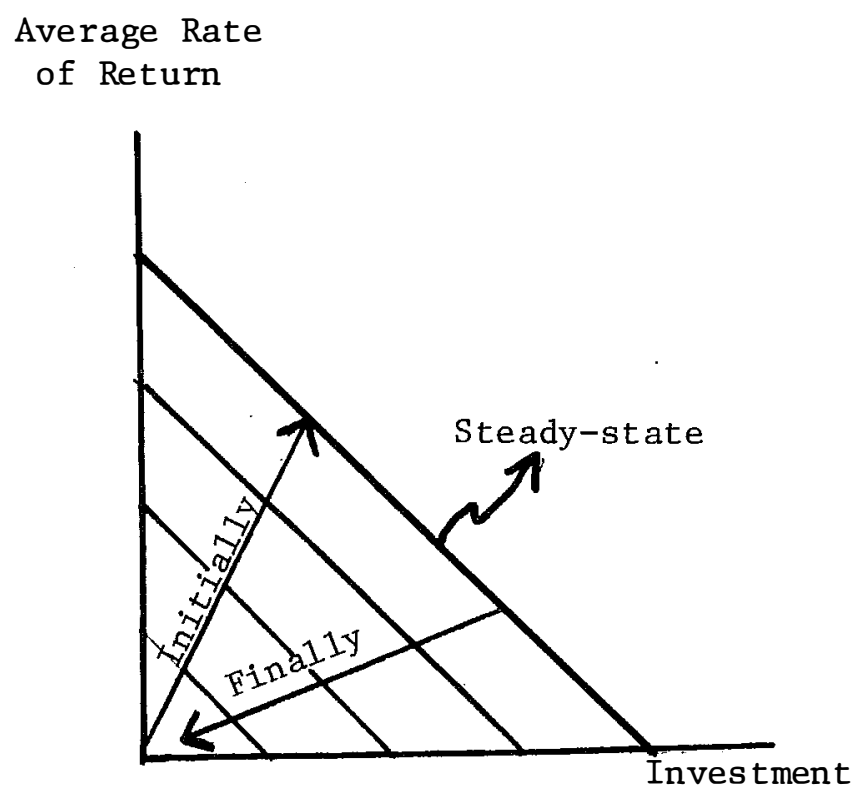

FIGURE 1

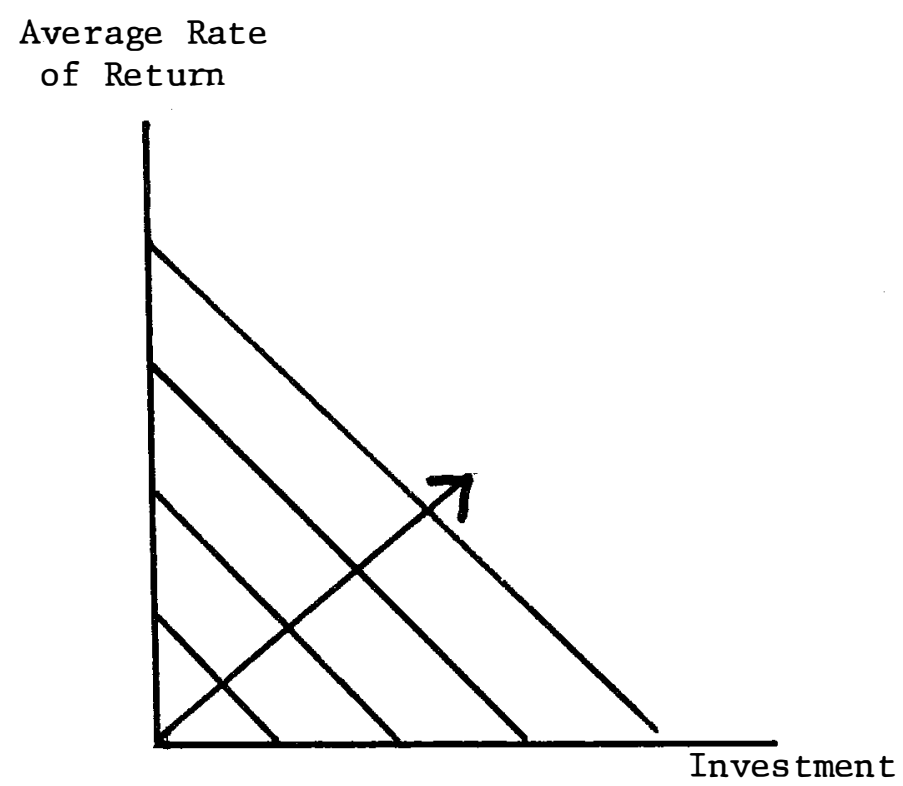

FIGURE 2 
where $\mathrm{MR}^{\mathrm{j}}(t)$ is the marginal return on investment at time $t$ for firm $j$. This equation can be interpreted to say that the deviation of the current marginal return from the rate of return required by shareholders must equal the (marginal) effect on future industry investment opportunities internalized by firm $j$.

The optimal investment behaviour of the monopolist and the competitive firm is determined by a common technique. Sum equation (4) over all firms in the industry to obtain:

$$
r m+r^{\prime} I=k m-e^{k t} \frac{d F}{d I} \int_{t}^{\infty} I e^{-k \tau} d \tau
$$

Define $\varepsilon(t)$ to be the elasticity of the industry average return function at time $t$ and divide equation (5) by $m$ to yield for the marginal rate of return of the individual firm:

$$
r\left(1+\frac{1}{m \varepsilon}\right)=k-\frac{e^{k t} \frac{d F}{d I} t^{f^{\infty} I e^{-k \tau} d \tau}}{m}
$$

The monopolist's behaviour is obtained by setting $\mathrm{m}=1$ in equation (6). Therefore, in contrast to the oligopolist, the monopolist fully internalizes his impact on future investment opportunities.

The competitive firm's behaviour is obtained by letting m become arbitrarily large in equation (6). As the number of firms in the industry increases, the elasticity (me) of each firm's average rate of return function on the left-hand side of equation (6) increases by the multiplier m. In the limit, as $m$ approaches infinity, the firm's average rate of return function becomes infinitely elastic - marginal rate of return on investment equals the average rate of return - in reflection of perfect competition. Also, as $\mathrm{m}$ increases, the second term on the right-hand 
side of equation (6) becomes progressively smaller so that the firm internalizes less of its impact on future investment opportunities. In the limit, under perfect competition, the firm completely disregards its impact on future investment opportunities. 6

Formally, we have proved the following theorems:

Theorem 1. The monopolist (oligopolist) will set the current marginal return on investment

$$
\left\{\begin{array}{l}
\text { greater than } \\
\text { equal to } \\
\text { less than }
\end{array}\right\}
$$

are a

$$
\left\{\begin{array}{l}
\text { decreasing } \\
\text { constant } \\
\text { increasing }
\end{array}\right\} \quad \text { function of current investment. }
$$

Theorem 2. The greater the degree of monopoly power which the firm has, the greater the divergence between the current marginal return on investment and the rate of return required by shareholders (provided $\frac{d F}{d I} \neq 0$ ).

Theorem 3. The competitive firm always sets the average (marginal) rate of return equal to the rate of return required by shareholders independent of future industry investment opportunities.

\section{Conclusion}

We have shown that the implicit assumption underlying the traditional analysis of the cost of capital is that the industry is perfectly competitive or in long-run steady-state equilibrium. Otherwise, the cost of capital is sensitive to market structure, since alternative structures have different implications for the rate of exploitation of industry investment opportunities over time. Further research is imperative, how- 
ever, if a definitive statement relating market structure and investment strategy is to be made. Market structure needs to be treated as a dynamic variable which can be affected by alternative industry investment rates. Such a theory presupposes a far more sophisticated model of dynamic oligopoly behaviour than we have presented. 


\section{Appendix}

The Cournot oligopoly model is solved as a control theory problem. ${ }^{7}$

Form the Hamiltonian:

(A1) $\quad H(t)=e^{-k t}\left[E^{j}(t)-I^{j}(t)+\lambda_{E}(t) r(I(t), t) I^{j}(t)+\lambda_{r}(t) F(I(t), r(I(t), t), t)\right]$

where $\lambda_{E}(t)$ and $\lambda_{r}(t)$ are the adjoint variables. The Maximum Principle requires that the optimal investment path satisfy the equation: ${ }^{8}$

(A2) $\frac{\partial \mathrm{H}}{\partial \mathrm{I}^{\mathrm{J}}}=0$ for a11 t.

In addition, the adjoint variables must satisfy the differential equations

(A3) $-\frac{\partial H}{\partial E^{j}}=\frac{d}{d t}\left(e^{-k t} \lambda_{E}\right)$

(A4) $-\frac{\partial H}{\partial r}=\frac{d}{d t}\left(e^{-k t} \lambda_{r}\right)$

and the transversality conditions

(A5) $\quad 1 i m e^{-k t} \lambda_{r}=0$ as $t \rightarrow \infty$

(A6) $\lim e^{-k t} \lambda_{E}=0$ as $t \rightarrow \infty$

Applying the Maximum Principle to our model yields

(A7) $r+r^{\prime} I^{j}=\frac{1}{\lambda_{E}}\left(1-\lambda_{r} \frac{d F}{d I}\right)$

(A8) $\frac{\mathrm{d} \lambda_{\mathrm{E}}}{\mathrm{dt}}=\mathrm{k} \lambda_{\mathrm{E}}-1$

(A9) $\frac{\mathrm{d} \lambda}{\mathrm{dt}}=\left(\mathrm{k}-\frac{\mathrm{dF}}{\mathrm{dr}}\right) \lambda_{r}-\lambda_{E_{1}} \mathrm{I}^{j}$

where $r^{\prime} \equiv \frac{d r}{d I}$.

Using the transversality conditions and noting that $\int_{0}^{t} \frac{d F}{d r} d r=1$ gives the following solutions to the differential equations (A8) and (A9): 
(A10) $\lambda_{E}=\frac{1}{k}$

(A11) $\lambda_{r}=\frac{e^{k t}}{k} \int_{t}^{f^{\infty}} I^{j} e^{-k \tau} d \tau$

Substituting these latter solutions into equation (A7) yields the optimality condition:

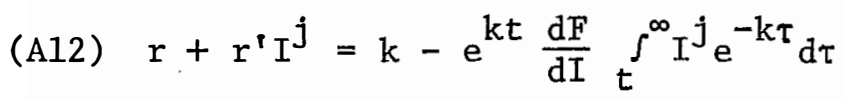




\section{FOOTNOTES}

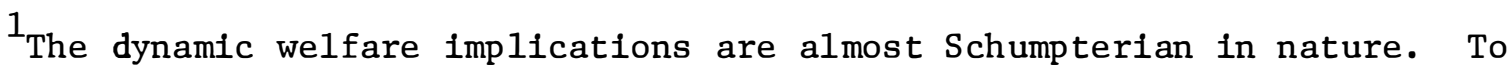
the extent that a competitive firm disregards the effect of its behaviour on future industry investment opportunities society is worse off and the monopolized industry is preferred. From a static resource allocation point of view, the reverse is true.

${ }^{2}$ See Cheung (1970)

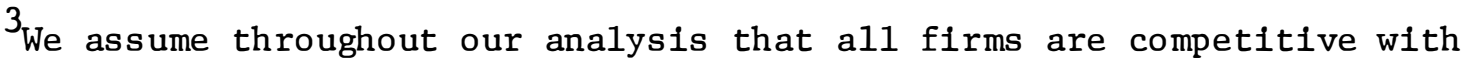
respect to the supply of funds. Thus, the rate of return required by shareholders is constant and independent of market structure. If the use of funds today affects the return that shareholders require in the future, additional time dependent externalities will be operative and the required rate will also be a function of market structure.

${ }^{4}$ Sufficient conditions for an optimum may require that $\mathrm{F}$ take on specific characteristics, i.e., concavity.

${ }^{5}$ From this point onwards, the time variable will normally be deleted for notational simplicity.

${ }^{6}$ Intuitively, as the number of firms in the Cournot setting becomes infinitely large, a natural extension to the competitive industry obtains. In fact, the rather stylized Cournot assumption that oligopolists disregard mutual interdependencies is an accurate description of the behaviour of competitive firms. Since each competitive firm alone is powerless to change industry parameters, mutual interdependencies, while recognized, are immaterial to the firm's investment behaviour. The competitive firm's powerlessness is manifest in its inability to earn a rate of return above the industry average should superior investment opportunities become available. As each firm tries to appropriate the potential benefits, similar efforts by a multitude of rivals will bid up the price of the investment and lower the yield so that each firm earns the Industry average rate of return. Similarly, the competitive firm disregards its impact on future industry investment opportunities since the potential benefits cannot be appropriated by the individual firm.

${ }^{7}$ See, for example, Hadley and Kemp (1971).

${ }^{8}$ In addition to the differential equations (2) and (3). 


\section{BIBLIOGRAPHY}

S. Cheung, "The Structure of a Contract and the Theory of a Non-Exclusive Resource," Journal of Law and Economics, Apri1 1970.

R. Coase, "The Problem of Social Cost," Journal of Law and Economics, October 1960.

E.J. E1ton and M.J. Gruber, "Valuation and Asset Selection Under Alternative Investment Opportunities," Journal of Finance, May 1976.

M.J. Gordon and L.I. Gould, "The Cost of Equity Capital: A Reconsideration and Extension," Mimeo, 1977.

G. Hadley and M.C. Kemp, Variationa1 Methods in Economics, North-Ho11and, 1971.

F. Modigliani and M.M. Miller, "The Cost of Capital, Corporation Finance, and the Theory of Investment," American Economic Review, June 1958.

and

, "Taxes and the Cost of Capital: A

Correction, American Economic Review, June 1963. 
Faculty of Business

McMaster University

WORKING PAPER SERIES

101. Torrance, George W., "A Generalized Cost-effectiveness Model for the Evaluation of Health Programs," November, 1970.

102. Isbester, A. Fraser and Sandra C. Castle, "Teachers and Collective Bargaining in Ontario: A Means to What End?" November, 1971.

103. Thomas, Arthur L., "Transfer Prices of the Multinational Firm: When Will They be Arbitrary?" (Reprinted from: Abacus, Vol. 7, No. 1, June, 1971).

104. Szendrovits, Andrew 2., "An Economic Production Quantity Model with Holding Time and Costs of Work-in-process Inventory," March, 1974.

111. Basu, S., "Investment Performance of Common Stocks in Relation to their Price-earnings Ratios: A Text of the Efficient Market Hypothesis," March, 1975.

112. Truscott, William G., "Some Dynamic Extensions of a Discrete LocationAllocation Problem," March, 1976.

113. Basu, S. and J.R. Hanna, "Accounting for Changes in the General Purchasing Power of Money: The Impact on Financial Statements of Canadian Corporations for the Period 1967-74," April, 1976. (Reprinted from Cost and Management, January-February, 1976).

114. Deal, K.R., "Verification of the Theoretical Consistency of a Differential Game in Advertising," March, 1976.

114a. Deal, K.R. "Optimizing Advertising Expenditures in a Dynamic Duopoly," March, 1976.

115. Adams, Roy J., "The Canada-United States Labour Link Under Stress," [1976].

116. Thomas, Arthur L., "The Extended Approach to Joint-Cost Allocation: Relaxation of Simplifying Assumptions," June, 1976.

117. Adams, Roy J. and C.H. Rummel, "Worker's Participation in Management in West Germany: Impact on the Work, the Enterprise and the Trade Unions," September, 1976.

118. Szendrovits, Andrew Z., "A Comment on 'Optimal and System Myopic Policies for Multi-echelon Production/Inventory Assembly Systems'," [1976].

119. Meadows, Ian S.G., "Organic Structure and Innovation in Small Work - Groups," October, 1976. 
120. Basu, S., "The Effect of Earnings Yield on Assessments of the Association Between Annual Accounting Income, Numbers and Security Prices," October, 1976.

121. Agarwal, Naresh C., "Labour Supply Behaviour of Married Women - A Model with Permanent and Transitory Variables," October, 1976.

122. Meadows, Ian S.G., "Organic Structure, Satisfaction and Personality," October, 1976.

123. Banting, Peter M., "Customer Service in Industrial Marketing: A Comparative Study," October, 1976. (Reprinted from: European Journal of Marketing, Vol. 10, No. 3, Summer, 1976).

124. Aivazian, V., "On the Comparative-Statics of Asset Demand," August, 1976.

125. Aivazian, V., "Contamination by Risk Reconsidered," October, 1976.

126. Szendrovits, Andrew Z. and George 0. Wesolowsky, "Variation in Optimizing Serial Multi-Stage Production/Inventory Systems, March 1977.

12], Agarwal, Naresh C., "Size-Structure Relationship: A Further Elaboration," March 1977.

128. Jain, Harish C., "Minority Workers, the Structure of Labour Markets and Anti-Discrimination Legislation," March, 1977.

129. Adams, Roy J., "Employer Solidarity," March, 1977.

130. Gould, Lawrence I. and Stanley N. Laiken, "The Effect of Income Taxation and Investment Priorities: The RRSP;" March 1977.

131. Callen, Jeffrey L., "Financial Cost Allocations: A Game-Theoretic Approach," March 1977.

132. Jain, Harish C., "Race and Sex Discrimination Legislation in North America and Britain: Some Lessons for Canada," May, 1977.

133. Hayashi, Kichiro. "Corporate Planning Practices in Japanese Multinationls." Accepted for publication in the Academy of Management Journal in 1978. 
Innis Ref.

HB

74.5

. R47

no. $134 a$ 